\title{
De Marokkanenpaniek: de sociale constructie van 'Marokkanen' als folk devils
}

\author{
Abdessamad Bouabid
}

\section{Het Marokkanenprobleem}

Sinds de immigratie van Marokkaanse gastarbeiders in de jaren 1960 en 1970 en de gezinsvorming en -hereniging in de jaren 1970 en 1980, heeft 'de Marokkaanse gemeenschap' op veel terreinen een succesvolle bijdrage geleverd aan de Nederlandse samenleving. Dit heeft zich onder andere gemanifesteerd in veel succesvolle ondernemers, politici, schrijvers, muzikanten, acteurs en topsporters. In de afgelopen vijf decennia zijn Marokkaanse Nederlanders op domeinen als onderwijs, arbeidsmarkt en huisvesting dan ook sterk vooruitgegaan en is inmiddels een Marokkaans-Nederlandse middenklasse ontstaan. ${ }^{1}$ Ondanks deze positieve ontwikkelingen ervaart 'de Marokkaanse gemeenschap' in Nederland, complex en gefragmenteerd als zij is, echter een negatief groepsimago gebaseerd op een groep mannelijke jongeren die 'uitblinken' in ernstige sociale problemen, in het bijzonder in criminaliteit, overlast en radicalisering. ${ }^{2}$

Dit negatieve groepsimago wordt voor een belangrijk deel geconstrueerd in negatieve en energieke maatschappelijke reacties in de media op grote en kleine incidenten, waarin Marokkaans-Nederlandse jongeren een rol spelen. De eerste keer dat 'Marokkanen' en criminaliteit in het middelpunt van de maatschappelijke aandacht komen, lijkt in 1988 te zijn geweest, toen een interne beleidsnotitie van de Amsterdamse gemeenteraad (Loef, 1988), met daarin verontrustende berichten over de toenemende criminaliteit onder 'Marokkaanse jongeren' in het Amsterdamse stadscentrum, werd gelekt naar de pers. Het op dat moment bestaande taboe op het koppelen van criminaliteit aan etnische groepen lijkt in die maatschappelijke reactie te zijn doorbroken (Werdmölder, 1989; Maas-de Waal, 1991; Bovenkerk, 2003a; Van Swaaningen, 2006). In de loop der jaren volgen meerdere grote incidenten waarop soortgelijke negatieve maatschappelijke reacties zich in de media ontvouwen: de rellen in Slotervaart $(1998,2007)$, de moord op Theo van Gogh (2004), de dreiging van de Hofstadgroep (2004-2006), de dood van 'tasjesdief' Ali El B. (2005), het Goudse bus-incident (2008), de rellen in Culemborg (2009-2010), het grensrechterincident (2012), de juweliersoverval in Deurne (2014) en de liquidaties binnen de 'Mocromafia'(2012-nu). Maar ook op 'kleinere' incidenten zoals: overlast op straat, in badplaatsen, het zwembad, de

1 Zie de reeks SCP-rapportages 'Rapportage Minderheden' van 1995 tot en met 2005 en SCP/CBSrapportages 'Jaarrapportage Integratie' van 2005 tot en met 2014.

2 Op de oververtegenwoordiging van Marokkaanse Nederlanders in deze sociale problemen zal in dit artikel niet verder worden ingegaan, omdat de focus primair ligt op de maatschappelijke reacties in de media op deze sociale problemen. Voor een uitgebreide behandeling van de oververtegenwoordiging in sociale problemen, zie de bovengenoemde SCP- en CBS-reeks, Buijs et al., 2006 (m.b.t. radicalisering) en Bovenkerk, 2014 (m.b.t. criminaliteit). 
bioscoop en in het uitgaansleven, homohaat en -geweld, antisemitisme, vrouwonvriendelijkheden, loverboys, jihadgangers, drugsrunners en roofovervallen. Met de alom bekende oververtegenwoordiging in criminaliteitscijfers, deze kleine en grote incidenten en de daaropvolgende maatschappelijke reacties zijn Marokkaans-Nederlandse jongeren in de afgelopen decennia het symbool geworden van overlast, criminaliteit en radicalisering en spreekt men inmiddels van 'het Marokkanenprobleem' en/of 'het Marokkanendrama' in wat men noemt 'het Marokkanendebat' (De Jong, 2007).

In 2003 stelt Bovenkerk dat deze maatschappelijke reacties op 'Marokkanen', die hij aanduidt als 'paniekreacties' of 'panikerende aandacht', moeten worden onderzocht (2003a, 2003b). Volgens hem zien we namelijk met alleen de focus 'op de oorzaken van criminaliteit bij de minderheden' anders 'niet meer dan de helft van het probleem' (2003a: 250). Deze maatschappelijke reacties op 'Marokkanen' in de media hebben mijns inziens nu dertien jaar later nog steeds onvoldoende aandacht gekregen in wetenschappelijk onderzoek. In dit artikel wordt dan ook gepoogd deze maatschappelijke reacties op de sociale problematiek van Marokkaanse Nederlanders in Nederland te exploreren en te begrijpen. Dit gebeurt aan de hand van de centrale vraag: 'Hoe ziet de maatschappelijke reactie op Marokkaans-Nederlandse jongeren in de media in Nederland eruit en hoe kan deze begrepen worden?'

\section{De morele paniek-theorie als conceptueel model}

Om deze maatschappelijke reactie te onderzoeken en te begrijpen, is gekozen voor een conceptueel model gebaseerd op de morele paniektheorie. Deze theorie voorziet ons namelijk van bruikbare sensitizing concepts (Blumer, 1954) waarmee sociale reacties van een dominante 'normale' meerderheid, ${ }^{3}$ in casu 'de Nederlanders', op sociaal deviante minderheidsgroepen, in casu 'de Marokkanen', onderzocht en begrepen kunnen worden. Deze theorie wordt in de jaren 1960 en 1970 ontwikkeld door zowel Cohen (1972, 2002) als Young (1971a, 1971b) als zij de negatieve maatschappelijke reacties onderzoeken op respectievelijk de Britse jeugdsubculturen the Mods en the Rockers en drugsgebruikende hippies in London. Zowel Cohen als Young beargumenteert op basis van empirisch onderzoek dat deze maatschappelijke reacties van de dominante 'normale' meerderheid als panikerend en misplaatst te kenschetsen zijn. Misplaatst wil zeggen dat deze maatschappelijke reacties zich manifest richten op actuele gebeurtenissen en sociale gedragingen, maar dat deze 'eigenlijk' gericht zijn op een latente morele dreiging. Deze maatschappelijke reacties zijn door deze 'misplaatsing' (een focus op het manifeste in plaats van het latente) disproportioneel ten aanzien van de actuele gebeurtenissen en sociale gedragingen, maar zeer zeker proportioneel ten aanzien van het latente 'ware probleem': een onderliggende bezorgdheid over en angst voor een mogelijke aantasting van de heersende moraal (the real problem: Ferrell

3 Mythische constructie van een sociale (morele, culturele) eenheid in het publieke debat dat als tegenhanger van de sociaal devianten fungeert ('wij' versus 'zij', the collective Self versus the Others). 
et al., 2008: 47-50; background anxieties: zie Garland, 2008: 15). Een morele paniekreactie is daarom dan ook een 'misplaatsing van een andere angst', 'een signifier van een dieper probleem' en 'een mystificatie van een diepere dreiging' die ontstaat uit een cultureel/moreel onbehagen of culturele/morele crisis (Ferrell et al., 2008: 47-50; Young, 2005, 2009, 2011); dit onderscheidt een morele paniek dan ook van een algemene 'mediahype' (vgl. Vasterman, 2004). Zo was bijvoorbeeld de morele paniek over drugs die Young in de jaren 1960 onderzocht een misplaatste reactie op het drugsgebruik door hippies in Notting Hill en was het 'ware probleem' de immoraliteit van de arbeidsethosverachtende hedonistische jongeren en hun hippiesubcultuur, die een bedreiging vormde voor de morele hegemonie van de hardwerkende en volwassen dominante meerderheid (Young, 1997: 9, 1971a, 1971b; Cohen, 2002). Waar subculturele theorieën de 'ware betekenis' (the real significance: Young, 2005) achterhalen van de ogenschijnlijke irrationaliteit van sociaal deviant gedrag, achterhaalt de morele paniektheorie het 'ware probleem' en de 'ware betekenis' van ogenschijnlijk irrationele en panikerende maatschappelijke reacties op sociale deviantie (Ferrell et al., 2015: 49).

Binnen de morele paniektheorie is gekozen voor de 'klassieke' morele paniektheorie van Cohen (1972, 2002). Binnen zijn conceptueel model worden de media gezien als belangrijkste arena van het publieke debat en wordt verondersteld dat maatschappelijke reacties sterk worden beïnvloed door betekenisgevingsprocessen die zich binnen deze arena afspelen (Cohen, 2002: 16; Critcher, 2003; Hall et al., 1978: 75-76; Young, 1971b; Krinsky, 2013: 2). In dit betekenisgevingsproces spelen enerzijds de media zelf een cruciale rol, omdat zij bepalen welke sociale problemen worden geadresseerd (en welke niet) en deze vervolgens definiëren (Cohen, 2002: xxiv). Anderzijds bieden de media ook een platform voor zogenoemde moral entrepreneurs, personen die sociale problemen aankaarten, definieren en anderen proberen te overtuigen van de waarheid van hun claims (Cohen, 2002; Becker, 1963; Hall et al., 1978: 16). Deze focus op 'de media' als primary definers, zij definiëren sociale problemen, en als secondary definers, zij presenteren en vertalen de sociale probleemdefinities van moral entrepreneurs (zie Cohen, 2002: xxiii-xxiv; Critcher, 2003), van sociale problemen in het conceptueel model van Cohen, levert ons enkele bruikbare sensitizing concepts op, waarmee de maatschappelijke reactie op 'Marokkanen' in de media kan worden onderzocht. In dit artikel worden zes sensitizing concepts uitgelicht, die door Cohen (2002) worden beschreven als belangrijke elementen van een morele paniek: 'overdrijving van feiten', 'voorspellingen', 'koppelingen', 'symbolisering', 'beelden' en verklaringen'. Deze morele paniekelementen zullen in de loop van dit artikel worden toegelicht.

\section{De kwalitatieve documentanalyse als analysemethode}

Altheide en Schneider (2013) beschrijven de kwalitatieve documentanalyse als een symbolisch-interactionistische analysemethode die handvatten biedt voor de analyse van de sociale constructie van de werkelijkheid in maatschappelijke reacties. Deze analysemethode is het beste te beschrijven als participerende observatie met documenten, waarbij documenten worden gezien als dragers van culturele objec- 
ten, symbolen en betekenissen die gezamenlijk de sociale werkelijkheid voor een samenleving vormen (Altheide \& Schneider, 2013). Het is de onderzoeker die in deze 'interactie' met documenten, deze documenten transformeert tot antwoorden aan de hand van een protocol waarop de eerdergenoemde sensitizing concepts in vraagvorm zijn opgenomen. Een protocol, met daarop vragen zoals welke beelden worden geschetst van de sociaal devianten en wat voor symbolisering vindt plaats, is in deze analyse toegepast op in totaal 363 documenten: 330 krantenartikelen uit de databank van LexisNexis Academic en 33 zelfgemaakte transcripten van televisie-uitzendingen die zijn bekeken via Uitzendinggemist.nl. De krantenartikelen zijn afkomstig uit De Telegraaf (TG), ${ }^{4}$ de Volkskrant (VK) en de Metro (ME) en de televisie-uitzendingen van Pauw \& Witteman (PW), NOVA (NO) en EenVandaag (1V). De verzamelde documenten zijn allemaal ingevoerd in het kwalitatieve data-analyseprogramma Atlas.ti, waarna vervolgens is gezocht naar de antwoorden op de vragen op het protocol aan de hand van de analysetechniek van de thematische codering. Tegelijkertijd is ook de analysetechniek van het open coderen gebruikt om te kijken welke antwoorden op de probleemstelling uit de data zelf opborrelen. Ten slotte zijn de verkregen antwoorden geanalyseerd met behulp van vergelijking, categorisering en conceptualisering (Hennink et al., 2011) in zogenoemde Network Views, een hulpmiddel in Atlas.ti om zowel thematische als open codes grafisch te categoriseren en/of te relateren.

De krantenartikelen en tv-uitzendingen die zijn geanalyseerd, zijn allemaal gepubliceerd of uitgezonden in de drie maanden na drie geselecteerde gebeurtenissen waarbij Marokkaans-Nederlandse jongeren een prominente rol spelen: 'de rellen van Slotervaart' (2007), 'het Goudse bus-incident' (2008) en 'de Culemborgse rellen' (2010). Een periode van drie maanden is gekozen, omdat bij alle drie de gebeurtenissen het aantal documenten in de derde maand sterk afnam. De drie gebeurtenissen zijn verder geselecteerd, omdat deze relatief recent zijn en relatief grote maatschappelijke reacties in de media hebben opgeroepen, dat wil zeggen dat zij de meeste documenten hebben opgeleverd in vergelijking tot de berichtgeving over andere 'Marokkanenincidenten' in de afgelopen tien jaar.

\section{Drie gebeurtenissen: Slotervaart 2007, Gouda 2008 en Culemborg 2009-2010}

Op zondag 14 oktober 2007 wordt Bilal B. in een politiebureau in Slotervaart door een agent doodgeschoten, nadat hij deze had aangevallen met een mes. Een dag later verzamelt een menigte mensen zich in de avond voor het politiebureau op het August Allebéplein. Rond 23.00 uur breken er rellen uit, waarbij het politiebureau wordt bekogeld met stenen en een auto in brand wordt gestoken. Het duurt tot middernacht voordat de politie de situatie onder controle heeft. In de acht dagen na deze openbare ordeverstoring op het August Allebéplein is het weer rustig in de wijk, op een reeks van ongeveer tien tot twintig heimelijk en 's nachts uitgevoerde autobranden na. De tweede gebeurtenis vindt twee jaar later plaats

4 In de bronverwijzingen in de tekst worden deze afkortingen gebruikt voor de kranten en televisieprogramma's. 
als op woensdag 10 september 2008 een buschauffeur in de Goudse wijk Goverwelle met een mes op de keel wordt beroofd van zijn kasgeld. Twee dagen later besluit vervoersmaatschappij Connexxion om geen bussen meer door de aangrenzende wijk Oosterwei te laten rijden. De derde gebeurtenis vindt plaats in de Culemborgse wijk Terweijde tijdens de jaarwisseling 2009-2010 en bestaat uit een reeks incidenten, waaronder de 'gebruikelijke' ongeregeldheden en autobranden van oud en nieuw, een mishandeling van een 49-jarige wijkbewoner, een mishandeling van de inzittenden van een auto die al dan niet opzettelijk een voortuin binnenrijdt en een groep jongeren die op 3 januari 2010 diezelfde straat binnenrijdt en enkele auto's en huizen met stenen bekogelt. In de media doen vervolgens allerlei verhalen de ronde waarin de incidenten worden beschreven als wraakacties tussen twee groepen over en weer.

\section{Een Marokkanenpaniek?}

\section{De overdrijving van de gebeurtenissen}

Volgens Cohen (2002, p. 19 e.v.) zijn in een morele paniek allereerst drie elementen te herkennen die de dreiging van gebeurtenissen 'overdrijven'. Zo worden feiten, zoals de ernst van het incident, het aantal deelnemende personen en de mate van geweld en de ontstane schade overdreven of verdraaid, worden voorspellingen van herhalingen of escalatie van de gebeurtenissen gedaan en worden koppelingen gelegd met andere reeds bestaande sociale problemen en angsten. In de drie geselecteerde gebeurtenissen vinden we deze drie elementen ook terug.

\section{- Slotervaart: 'meerdaagse' rellen van Marokkaanse probleemjongeren}

De rellen op het August Allebéplein beperken zich tot de maandagavond 15 oktober 2007 (Bouabid, 2016), maar in het mediadiscours wordt echter een beeld geschetst van 'meerdaagse' rellen in Slotervaart:

Presentator Joost Karhof: 'We gaan het vanavond hebben over de rellen in het Amsterdamse Slotervaart. (...) Het stadsdeel heeft een roerige week achter de rug. Jonge raddraaiers zorgden dag na dag voor onrust. Laten we even kijken naar een overzicht.' (NO, 17-10-2007)

'De Amsterdamse fractievoorzitter van de democraten hield zijn pleidooi gisteravond in debat met stadsdeelvoorzitter Ahmed Marcouch van Slotervaart. Een maand nadat Marokkaanse criminelen een week lang voor ongeregeldheden zorgden en autobranden stichtten is daar de rust weer terug.' (TG, 21-11-2007: 33)

Dit beeld van meerdaagse rellen wordt in verschillende documenten versterkt door herhalingen en opsommingen van dezelfde incidenten, namelijk de rellen van de maandagavond en de nachtelijke autobranden, en gezamenlijk gelabeld als 
de 'rellen van Slotervaart' (vb. 1V, 16-10-2007; ${ }^{5}$ PW, 17-12-2007). Een andere overdrijving is te vinden in het aantal personen waar de dreiging van uitgaat. Waar men zich in de eerste reacties focust op twintig (vb. VK, 16-10-2007: 3) tot zestig (vb. 1V, 27-10-2007) jongeren, verlegt de aandacht zich in een later stadium naar 150 (vb. VK, 1-12-2007: 2) tot 1500 probleemjongeren in AmsterdamWest (vb. TG, 1-11-2007: 37). Tegelijkertijd worden ook dreigende voorspellingen gedaan, die naderhand niet uitkomen, zoals meer rellen (vb. VK, 19-10-2007: 3), rellen die zullen overslaan naar andere steden (vb. TG, 23-10-2007: 35) en meer Bilal B.'s en 'Marokkaanse' probleemjongeren die zullen opgroeien in Nederland (vb. TG, 19-10-2007: 5). Ook wordt deze gebeurtenis gekoppeld aan andere sociale problemen en angsten, zoals: de massale Franse banlieu-rellen van 2005 (vb. NO, 18-10-2007), terrorisme, vanwege de vermeende banden die Bilal B. zou hebben met de Hofstadgroep (vb. journalist Siem Eikelenboom: NO, 15-10-2007) en een steekpartij op het TeC College in Slotervaart van een week eerder (vb. 1V, 19-10-2007), dat geen verband heeft met de dood van Bilal B. of de rellen.

\section{- Gouda: een 'Marokkaanse' dader in het 'Marokkaanse Oosterwei'}

Op de beroving van de buschauffeur en het besluit van Connexxion om geen bussen meer te laten rijden door Oosterwei volgt een negatieve maatschappelijke reactie die zich primair richt op de wijk Oosterwei en 'Marokkanen'. Hierin wordt gesproken over een 'Marokkaanse' dader van het busincident (vb. TG, 16-9-2008: 5; Geert Wilders in: PW, 23-9-2008), een reeks van eerdere incidenten op de desbetreffende buslijn in Oosterwei (vb. ME, 15-9-2008: 3), 'Marokkaanse probleemjongeren' in Oosterwei (vb. TG, 16-9-2008: 5) en zelfs van 'rellen' in de wijk (vb. PW, 25-9-2008). Dit blijkt een overdrijving en verdraaiing van feiten te zijn, wanneer achteraf blijkt de etniciteit van de nog gezochte dader onbekend is, de overval op de buschauffeur niet plaatsvond in de 'Marokkanen-probleemwijk' Oosterwei, maar in het 'autochtone' Goverwelle en slechts drie van die reeks van negentien incidenten op de desbetreffende buslijn hebben plaatsgevonden in Oosterwei (zie ook Nijpels \& Van de Beek, 2012). Verder worden voorspellingen gedaan van escalatie van de problematiek met 'Marokkaanse jongeren', niet alleen in Gouda, maar in het hele land (vb. TG, 20-9-2008: 6; NO, 25-9-2008), spreekt men van een volgende lichting 'Marokkaanse' probleemjongeren die eraan zit te komen (vb. VK, 16-9-2008: 12) en voorspelt PVV-leider Geert Wilders een 'Islamitische Intifada' (1V, 19-9-2008). Dit Goudse busincident wordt vervolgens ook gekoppeld aan eerdere incidenten met 'Marokkanen', zoals de agressie tegen ambulancepersoneel in Amsterdam (vb. TG, 19-9-2008: 1) en de problematiek met 'Marokkaanse' jongeren in andere gemeenten zoals Ede (vb. TG, 17-9-2008: 12), Culemborg (NO, 25-11-2008), Nijmegen (vb. TG, 25-9-2008: 3) en Arnhem (TG, 28-10-2008: 1).

5 Vanwege het grote aantal verwijzingen naar krantenartikelen en tv-programma's zijn deze bronnen niet opgenomen in de literatuurlijst, maar worden ze in de loop van de tekst afgekort (i.v.m. de leesbaarheid) weergegeven: naam krant of tv-programma, dag/maand/jaar: paginanummer. 


\section{- Culemborg: 'Etnische rellen' tussen Marokkanen en Molukkers}

Afgezien van de 'gebruikelijke' nieuwjaarsonrust 2009-2010 en de drie eerdergenoemde ernstige incidenten op 1 en 3 januari 2010, wordt in deze maatschappelijke reacties, dit keer middels brand- en oorlogsmetaforen (vb. 'in staat van oorlog': TG, 5-1-2010: 5; 'veldslag': VK, 2-1-2010: 3; 'vredesbesprekingen' 1V, 6-1-2010; 'veenbrand': VK, 8-1-2010: 11), wederom een beeld geschetst van rellen die de wijk dagenlang in de greep houden (vb. TG, 11-1-2010: 6). De overdrijving bij de Culemborgse gebeurtenissen is daarnaast ook te vinden in de 'etnisering' van de gebeurtenissen. Er wordt al snel (vb. TG, 2-1-2010: 3) en structureel gesproken van rellen tussen 25 (vb. NO, 5-1-2010) tot 200 (vb. VK, 5-1-2010: 1) 'Marokkanen en Molukkers' in Culemborg, ondanks de afwezigheid van etnisch gekleurde beweegredenen, de aanwezigheid van enkele deëtniserende claims dat het slechts gaat om twee conflicterende groepen jongeren (vb. VK, 5-1-2010: 1) of families (PW, 5-1-2010) (zie ook Adang et al., 2010) en berichten over het probleemloos samenleven van de overige ruim 2000 Marokkaanse en 700 Molukse Nederlanders die de stad Culemborg telt (vb. VK, 9-1-2010: 3). Hierbij wordt ook weer gebruikgemaakt van niet uitgekomen voorspellingen van 'meer rellen' die zullen volgen (vb. NO, 04-01-2010) en 'Marokkanen' en 'Molukkers' die vanuit het hele land naar Culemborg zullen trekken om zich te mengen in dit 'etnische conflict' (vb. TG, 5-1-2010: 1). De dreiging wordt verder vergroot als ook hier koppelingen worden gelegd met andere angsten en problemen, bijvoorbeeld met andere vermeende 'etnische botsingen' in het verleden, zoals die in Tiel in 1995 tussen 'Marokkanen en Molukkers' (VK, 6-1-2010: 3) en die na de moord op Theo van Gogh in 2004 tussen 'Turkse jongeren' en 'Lonsdale-jongeren' in Venray en 'allochtone en autochtone jongeren' in Helden (NO, 4-1-2010) en ten slotte met allerlei andere 'Marokkanen-incidenten' uit het verleden (vb. TG, 14-1-2010: 6; TG, 13-2-2010: 3).

\section{Symbolisering van 'de Marokkaan' als folk devil}

Binnen een morele paniekreactie vindt naast overdrijving ook symbolisering plaats. Dit wil zeggen dat gebeurtenissen en de daarin gemanifesteerde sociaal deviante gedragingen en sociale problemen, middels symbolisering worden gekoppeld aan een grotere specifieke groep mensen, zogenoemde folk devils, die worden gepresenteerd als de belichaming van het immorele kwaad (Cohen, 2002: 2, 27-30), in casu 'de Marokkanen'.

\section{- Slotervaart: het epicentrum van 'het Marokkanenprobleem'}

'Het August Allebéplein in Amsterdam-West, waar twee agenten door de schizofrene Bilal B. werden neergestoken, is al jarenlang het epicentrum van de Marokkanenkwestie.' (TG, 19-10-2007: 5)

De gebeurtenissen in Slotervaart worden in het mediadiscours middels twee symboliseringsprocessen gekoppeld aan 'de Marokkaan'. Enerzijds wordt Bilal B. geconstrueerd als 'Marokkaanse folk devil' door een vervlechting van drie besproken thema's: 'Bilal is een psychiatrische patiënt', waarin zijn psychiatrisch verle- 
den uitvoerig wordt besproken (vb. VK, 17-10-2007: 2), 'Bilal is een crimineel', waarin zijn criminele verleden wordt uitgelicht (vb. TG, 16-10-2007: 3) en 'Bilal is een terrorist', bestaande uit vermeende banden van Bilal B. met Mohammed B. en enkele leden van de Hofstadgroep (vb. NO, 15-10-2007). Deze drie thema's worden vervolgens weer gekoppeld aan de Marokkaanse etniciteit door Bilal B. expliciet een 'Marokkaan' (vb. ME, 15-11-2007: 16) te noemen en hem te linken aan de oververtegenwoordiging van Marokkaans-Nederlandse jongeren in psychische (vb. VK, 23-10-2007: 12) en radicaliseringsproblematiek (vb. TG, 23-10-2007: 6). In een tweede symboliseringsproces worden 'Marokkaanse jongeren' aan de hand van drie andere met elkaar verweven thema's aangewezen als 'Marokkaanse folk devils'. In het meest prominente thema, 'er zijn rellen in Slotervaart', wordt gesproken van onrust en rellen in de wijk en worden deze veelvuldig gekoppeld aan de rellen van 'etnische minderheden' in Frankrijk (vb. PW, 17-10-2007; NO, 18-10-2007). In een ander thema, 'de relschoppers zijn Marokkanen', wordt de focus expliciet gelegd op de Marokkaanse etniciteit door te spreken van bijvoorbeeld 'Marokkaanse relschoppers' (vb. VK, 27-10-2007: 7) of 'relmocro's' (vb. ME, 24-10-2007: 16) en hen te koppelen aan andere sociale problemen die deel uitmaken van de reeds bestaande notie van 'het Marokkanenprobleem', zoals: criminaliteit (vb. VK, 19-10-7: 3), overlast (vb. 1V, 27-10-2007) en probleemjongeren (vb. VK, 20-10-2007: 22-23). In het laatste thema, 'Slotervaart is een probleemwijk', wordt gewezen op de relatief veel sociale problemen en achterstanden waar Slotervaart als prototype 'probleemwijk' mee te kampen zou hebben (vb. PW, 17-12-2007) en wordt wederom expliciet verwezen naar de oververtegenwoordiging van 'Marokkanen' in sociale problematiek (vb. VK, 1-11-207: 3). Beide processen symboliseren Bilal B. en de 'relschoppers' als ideaaltypische Marokkaanse folk devils en Slotervaart als typische probleemwijk van 'Marokkaanse' jongeren.

\section{- Gouda: Marokkanisering van het busincident}

Een eerste symboliseringsproces ontstaat wanneer Oosterwei net als Slotervaart wordt geconstrueerd als thuisbasis van de 'Marokkaanse folk devils'. Hoewel 'Marokkanen' en Oosterwei niets met het busincident te maken hebben, richten de maatschappelijke reacties zich toch primair op deze bevolkingsgroep én de woonwijk met een relatief hoog aantal bewoners van Marokkaanse afkomst (50\% in 2008: CBS StatLine, 2013). Er wordt gesproken van een: 'achterstandswijk' (vb. 1V, 19-9-2008), 'probleemwijk' (vb. ME, 26-9-2008: 2), 'overlastwijk' (VK, 20-9-2008: 9), 'getto' (vb. TG, 16-9-2008: 5), 'banlieutje' (VK, 27-9-2008: 2), 'no go area' (vb. ME, 6-10-2008: 12), 'vrijstaat voor tuig' (TG, 20-9-2008: 5), 'allochtone wijk' (VK, 16-9-2008: 3), 'schotelwijk' (ME, 15-9-2008: 14), 'Marokkaans getinte buurt' (VK, 26-9-2008: 2), 'Marokkaanse enclave' (ME, 15-9-2008: 14) en 'Klein Marokko' (vb. ME, 19-9-2008: 2), waar bewoners, passanten en nu vooral buschauffeurs frequent zouden worden 'bedreigd', 'bespuugd', 'geslagen' en 'beroofd' door 'Marokkaanse jongeren' (vb. ME, 15-9-2008: 3; TG, 16-9-2008: 5). Deze symbolisering, bestaande uit koppelingen tussen de wijk Oosterwei, 'het bus-incident', 'overlast en criminaliteit' en 'Marokkanen', wordt verder versterkt door een tweede en meer algemeen symboliseringsproces dat plaatsvindt in het politieke debat. Hierin worden de Goudse gebeurtenissen naar een nationaal niveau getild 
en geschaard onder 'het Marokkanenprobleem' en wordt tegelijkertijd ook een vermeende softe, politiek correcte en ontkennende houding van de overheid en politiek ten aanzien van deze lokale en nationale 'Marokkanenproblematiek' bekritiseerd (vb. PW, 25-9-2008; VK, 26-9-2008: 2; 1V, 19-9-2008). Zo koppelt VVD-Tweede Kamerlid Henk Kamp bijvoorbeeld na het spoeddebat over Gouda, deze gebeurtenissen aan de oververtegenwoordiging van Marokkaanse Nederlanders in de criminaliteit én aan de vermeende ontkenning van dit probleem door de Goudse burgemeester Wim Cornelis:

'Kijk, het is... in die brief die we vandaag gekregen hebben van het Kabinet, daar staat dus in dat van de Marokkanen van de 18 tot en met de 24 jaar, dat daar één op de vijf verdacht is van één of meerdere criminele feiten, misdrijven en daar ook vaak voor veroordeeld is. Als je kijkt naar de nog jongere Marokkanen, bijvoorbeeld in een stad als Tilburg, daar gaat het om één op de vier. Als je kijkt naar Rotterdam, dan is er in een bepaalde leeftijdsgroep van Marokkaanse jongens, één op de twee is al geregistreerd in de politiedossiers, één op de twee! Dan is het toch al zo ver uit de hand gelopen. Om dat nog te ontkennen [refererend aan uitspraken van Wim Cornelis], ja, dan ben je echt niet meer van deze wereld.' (PW, 25-9-2008)

\section{- Culemborg: Arena van etnische rellen}

De maatschappelijke reactie op de Culemborgse gebeurtenissen kent drie thema's. In de eerste vier dagen na de jaarwisseling worden de gebeurtenissen weergegeven en besproken onder het thema 'gebruikelijke nieuwjaarsonrust' (vb. VK, 2-1-2010: 3) en speelt etniciteit niet of nauwelijks een rol. Dit thema wordt echter binnen enkele dagen verdrongen door een symboliseringsproces waarin de Marokkaanse en Molukse etniciteiten centraal staan, bestaande uit twee nauw verweven thema's. In het eerste thema, 'het zijn rellen', wordt verslag gelegd van de rellen en spreekt men over de verkondigde noodverordening, afsluiting van delen van de wijk, preventieve arrestaties en inzet van de Mobiele Eenheid om de rellen tussen 'Marokkanen en Molukkers' te kunnen stoppen (vb. 1V, 4-1-2010; TG, 6-1-2010: 3). In het tweede thema, 'het is een etnisch conflict', gaat men dieper in op de vermeende spanningen, conflicten en gewelddadigheden tussen deze 'rellende Marokkanen en Molukkers'. Zo wordt er veelvuldig gewezen op eerdere vermeende conflicten tussen beide bevolkingsgroepen (vb. VK, 6-1-2010: 3), wordt hun immigratiegeschiedenis als contextinformatie aangehaald (vb. VK, 9-1-2010: 29) en worden enkele 'experts' met zogenaamde 'etnische expertise' geraadpleegd die wijzen op etnische componenten van het probleem, zoals Dick Corporaal, de voorzitter van het Interventieteam Interetnische Spanningen, in gesprek met presentatrice Clairy Polak:

Corporaal: 'Het is op dit moment, lijkt het alle kenmerken van een etnisch conflict te hebben, maar daar zitten natuurlijk ook, ik heb vandaag meer filmpjes gezien over Culemborg. Daar zitten ook allerlei ettertjes die de zaak proberen te verzieken en dat is een deel maar van de Marokkaanse gemeenschap, dus, en er zitten ook ettertjes bij de Molukkers, en dat zul je wel moeten aan- 
pakken en ook hard moeten straffen waar men scheef gaat. Ja, en ik heb wel soortgelijke situaties gehad...'

Polak: '... als burgemeester?'

Corporaal: 'Als burgemeester. Dat was in Leerdam. Zeker ook met de Molukse gemeenschap, die zijn af en toe ook, ja, actie en reactie, en die reageren vaak fel.'

Polak: 'Maar u zegt, zeker ook met een Molukse gemeenschap? Wij krijgen hier de indruk dat het vooral de Marokkanen zijn die hier de agressor zijn, zou ik maar zeggen. Die Molukse gemeenschap vergt ook een speciale aanpak?'

Corporaal: 'Ik vind van wel. Dat is mijn ervaring in ieder geval, in mijn ervaringen in ieder geval, dat men ook graag nog eigenlijk ook vrij snel de richting van eigenrichting op wil en ik zie in Culemborg gebeuren dat men zegt: "Wij houden zelf de wacht, want we vertrouwen de politie niet.”' (NO, 4-1-2010)

Het laatste thema, 'het is geen etnisch conflict', bestaat uit een klein aantal deetniserende claims waarin men wijst op rivaliserende jeugdgroepen (vb. NO, 5-1-2010) en/of families (PW, 5-1-2010: 1) en op het harmonieus samenleven van de rest van de Marokkaanse en Molukse gemeenschappen in Culemborg (vb. VK, 6-1-2010: 3). Dit laatste thema wordt net als het eerste thema 'gebruikelijke nieuwjaarsonrust' echter ondergesneeuwd door de twee dominantere thema's waarin de gebeurtenissen worden geconstrueerd als 'rellen tussen Marokkanen en Molukkers' en waarin vooral de 'Marokkaan' als folk devil wordt gesymboliseerd:

'Een Nederlandse vrouw woont er [red. de Culemborgse wijk Terweijde] dan ook "perfect", haar hele leven al. Ze is op de hand van de Molukkers, zegt ze. Het zijn de Marokkaanse crimineeltjes, de onopgevoede jongens, die het hebben gedaan. Ze hebben nergens respect voor.' (VK, 5-1-2010: 3)

\section{'De Marokkaan' als de ander}

Binnen deze symboliseringsprocessen in een morele paniekreactie worden vervolgens beelden geschetst van de deviante aard van deze aangewezen folk devils en worden verklaringen aangedragen voor hun deviante gedragingen (Cohen, 2002: 39-49). Dit gebeurt middels een proces van othering, waarin the Self positief wordt gedefinieerd door deze te distantiëren van the Other, die vervolgens negatief wordt gedefinieerd (Young, 2007: 5-7). In deze paragraaf worden de beelden en verklaringen die gevonden zijn in de drie onderzochte maatschappelijke reacties gezamenlijk beschreven. Deze beelden en verklaringen leggen drie processen van othering van 'de Marokkaan' bloot: 'de Marokkaan' als de morele ander, als de culturele ander en als folk saint.

\section{- 'De Marokkaan' als de morele ander}

Het eerste beeld van 'de Marokkaan' dat in alle drie de reacties terug te vinden is, is dat van de 'overlastgever' die de straten, buurten en wijken in Nederland 'terroriseert': 
'Geen bevolkingsgroep is in 2008 zo vaak in het nieuws geweest als de Marokkaanse Nederlanders. In talloze gemeenten (Amsterdam, Culemborg, Ede, Gouda, Nijmegen, Utrecht, Zandvoort: het is maar een greep) waren er problemen met groepen jongeren van Marokkaanse afkomst. Meermaals kwamen de "straatterroristen" - de term is van PPV-leider Wilders - aan de orde in de Tweede Kamer. De kwestie liep in oktober politiek zo hoog op dat vier ministers met tien burgemeesters bijeenkwamen om te bezien wat er aan de overlast kan worden gedaan. Ook elders werd alarm geslagen. Een groep van voornamelijk allochtone publicisten, onder wie televisiemaker Prem Radhakishun, riep onlangs alle Nederlanders op de Marokkaanse jongeren aan te spreken op hun "beestachtige" gedrag. Hoe komt het toch dat de Marokkaanse jongeren in Nederland zoveel hinder veroorzaken?' (VK, 10-12-2008: 2)

Dit beeld ontstaat voor een belangrijk deel door de koppeling van de Marokkaanse etniciteit aan verschillende overlastgevende gedragingen zoals: 'hangen' (vb. VK, 20-10-2007: 22-23), 'rondscheuren' met scooters en auto's (vb. 1V, 19-9-2008), 'wegen blokkeren' (ME, 15-9-2008: 3), 'bekogelen' met 'stenen' (vb. VK, 27-10-2007: 15), 'tomaten' en 'eieren' (TG, 24-10-2008: 1) en het 'uitschelden' (vb. PW, 19-9-2007), 'intimideren' (vb. PW, 5-1-2010), 'bedreigen' (vb. VK, 3-11-2008: 14), 'bespugen' (vb. VK, 5-1-2010: 3) en 'belagen' van mensen (vb. TG, 6-10-2008: 6). Naast deze gedragingen worden ook specifieke slachtoffers van de 'Marokkaanse' overlastgever genoemd, zoals: buurtbewoners (vb. PW, 3-10-2008), passanten (vb. TG, 20-9-2008: 5), winkeliers (vb. PW, 5-1-2010), buschauffeurs (vb. ME, 21-9-2008: 1), joden (VK, 27-9-2008: 12), homoseksuelen (vb. VK, 15-12-2007: 15), vrouwen (vb. VK, 16-9-2008: 12) en hulpverleners (vb. ME, 16-9-2008: 2). Dit beeld gaat gepaard met labels zoals: 'overlastgevers' (vb. VK, 16-9-2008: 12), 'tuig' (vb. TG, 6-1-2010: 3), 'raddraaiers' (vb. TG, 19-2-2010: 3), 'kut-Marokkanen' (vb. VK, 1-12-2007: 3) en allerlei varianten op 'etters' (ettertjes, etterbakken, etterjochies: vb. ME, 17-10-2008: 12), 'snotneuzen' (snottebellen, snotjongens: vb. PW, 3-10-2008) en 'straatjongeren' (straattuig, straatterroristen en straatschuimers: vb. VK, 8-1-2010: 11).

Een tweede beeld dat wordt geschetst is 'de Marokkaan' als 'crimineel', wat ontstaat door koppelingen van de Marokkaanse etniciteit aan het criminaliteitsprobleem, zoals bijvoorbeeld minister van Binnenlandse Zaken Guusje ter Horst doet bij Pauw \& Witteman:

Ter Horst: 'Nou wat ik zou willen zeggen, er wonen 16 miljoen mensen in Nederland, laten ze nou eens voor zichzelf beoordelen wat hun problemen zijn, wat de problemen zijn in hun wijk. Er zijn problemen met Marokkanen. We weten ook dat Marokkanen en ook andere bevolkingsgroepen als het gaat om criminaliteit vaker in de statistieken voorkomen, dus dat betekent ook dat je daar rekening mee moet houden. En er is niemand in het kabinet en ook niemand in de Tweede Kamer die dat vergoelijkt en die zegt van: "We kijken de andere kant op, we laten die Marokkaanse jongeren gewoon hun gang gaan." Absoluut niet. Maar het gaat er wel om de effectieve, om de meest 
effectieve manier te kiezen om te zorgen dat die jongeren hun gedrag veranderen.'

Pauw: 'Is het effectief om de etniciteit te benoemen? Zoals u wilt en ook dat het gewoon gefiled wordt en dat er in een dossier staat, zelfs als je geboren bent in Amsterdam, en dus niet in Marokko, dat je Marokkaan bent?'

Ter Horst: 'Ik denk dat als het van belang is, als je zeg maar je culturele achtergrond van belang is voor het gedrag dat je vertoont, voor de uitingen die je doet, dan is het ook relevant dat te registreren. Ik heb ook gezegd als Marokkanen een probleem veroorzaken in een wijk of als er andere etnische groepen zijn die niet een probleem veroorzaken, maar die een probleem hebben en je wilt dat probleem aanpakken, of je wil het probleem oplossen, dan is het zinvol om die etnische achtergrond, om die te registreren. Dus het kan gaan om Marokkanen die een probleem veroorzaken, die je wil aanpakken, waar je de Marokkaanse gemeenschap op wilt aanspreken, dan is het dus relevant om te weten dat die problemen door Marokkanen worden veroorzaakt, maar het kan ook gaan om iets heel anders, bijvoorbeeld diversiteitsbeleid.' (PW, 23-09-2008)

'De Marokkaan' wordt daarnaast ook specifiek gekoppeld aan delictsvormen als: 'diefstal' (vb. PW, 17-10-2008), 'beroving' (vb. TG, 4-10-2008: 3), 'autokraak' (vb. 1V, 16-10-2007), 'inbraak' (vb. VK, 9-1-2010: 3), 'mishandeling' (vb. TG, 21-9-2008: 3), 'huiselijk geweld' (vb. VK, 17-10-2007: 13), 'bedreiging' (vb. PW, 17-10-2008), 'vandalisme' (vb. ME, 15-11-2007: 16) en natuurlijk 'rellen' (vb. NO, 4-1-2010). Veelvoorkomende labels bij dit beeld zijn allerlei varianten op: criminelen (vb. 'hardcore criminelen': PW, 1-12-2008; 'boefjes': ME, 1-11-2007: 1), probleemjongeren (vb. 'risicojongeren': VK, 6-11-2007: 15; 'randgroepjongeren': VK, 1-12-2007: 3) en 'relschoppers' (vb. 'reljeugd': TG, 25-9-2008: 3; 'relmocro's': 24-10-2007: 16).

Naast deze twee gedragingen van criminaliteit en overlast wordt ook een aantal karaktertrekken gekoppeld aan 'de Marokkaan'. Een groep van dergelijke karakterbeelden is samen te vatten als 'onaantastbaar'. 'De Marokkaan' heeft bijvoorbeeld het gevoel dat 'niemand hem tegen kan houden' (TG, 19-10-2007: 5) en hij 'doet wat hij wil' (NO, 7-1-2010), is 'respectloos' (vb. VK, 26-10-2007: 11) en 'gewetenloos' (vb. PW, 17-10-2007), denkt 'boven de wet' te staan (TG, 6-1-2010: 3), heeft 'schijt aan alles' en iedereen (vb. VK, 6-1-2010: 3) en voelt zich ook 'superieur aan de Nederlander' (VK, 26-10-2007: 11). Een tweede groep beelden is samen te vatten als 'kansloos'. 'De Marokkaan' behoort bijvoorbeeld tot 'de onderklasse' (vb. NO, 18-10-2007), is 'laag opgeleid' (vb. PW, 1-10-2008), heeft een 'taalachterstand' (VK, 10-11-2007: 5), is 'werkloos' (VK, 16-1-2010: onbekend) en/of heeft een 'uitkering' (VK, 15-12-2007: 15) en profiteert van allerlei 'subsidies' (1V, 19-9-2008). Hij heeft verder een gebrek aan: 'discipline' (VK, 17-10-2007: 13), 'arbeidsethos' (PW, 17-12-2007), 'zelfkritiek' (TG, 19-10-2007: 3), 'burgerzin' (PW, 25-9-2008) en 'toekomstperspectief' (PW, 16-10-2007) en wil 'niet geholpen worden' (TG, 19-10-2007: 5), is 'moeilijk bereikbaar' voor hulpverleners (1V, 27-10-2007) en is ondanks 'vele investeringen' (PW, 17-12-2007) 'niet meer te redden' (NO, 19-10-2007). Ook heeft 'de Marokkaan' te maken met 
enkele psychologische problemen. Hij heeft niet alleen last van 'psychische stoornissen' (vb. VK, 10-12-2008: 2), maar is ook 'depressief' (VK, 23-10-2007: 12) en 'gefrustreerd' (vb. VK, 20-10-2007: 22-23), voelt zich 'niet begrepen' (VK, 9-1-2010: 29) en is 'agressief' (vb. VK, 3-10-2008: 1). Ten slotte wordt ook een vijandige houding ten aanzien van Nederland geschetst, zoals 'wantrouwen' (vb. PW, 5-1-2010) en 'minachting' (vb. VK, 2-11-2007: 11) jegens de Nederlandse overheid die overal de schuld van krijgt en de 'Nederlandse media' die 'de Marokkaan' zwart zouden maken (vb. VK, 16-1-2010: onbekend).

\section{- De Marokkaan als culturele ander}

'De Marokkaan' wordt niet alleen geconstrueerd als iemand met een andere moraliteit (andere ideeën over goed en kwaad), maar ook als iemand die van 'buiten' Nederland afkomstig is, oftewel: de 'culturele ander'. Dit gebeurt onder andere middels labels die 'de Marokkaan' binnen de Marokkaanse en/of buiten de dominante 'normale' Nederlandse cultuur plaatsen, zoals: 'Marokkanen' (vb. 1V, 6-1-2010), 'Marokkaanse' (vb. NO, 25-11-2008), 'Marokkaantjes' (vb. TG, 5-1-2010: 5), 'allochtonen' (vb. ME, 19-12-2007: 18), '(im)migranten' (vb. ME, 6-10-2008: 12), 'buitenstaanders' (VK, 15-12-2007: 15) en 'nieuwkomers' (ME, 13-12-2007: 33) of door te spreken van 'mislukte integratie' in de Nederlandse cultuur (vb. VK, 17-10-2007: 13). Daarnaast gebeurt deze sociale constructie tot 'culturele ander' door het koppelen van de eerder besproken sociaal deviante gedragingen van 'de Marokkaan' aan 'zijn cultuur' (culturisme: Schinkel, 2008). Deze koppeling is vaak niet meer dan het expliciet noemen van de Marokkaanse cultuur of achtergrond als oorzaak voor deze gedragingen, zoals door criminoloog Hans Werdmölder:

'Het heeft wel degelijk te maken met de Marokkaanse cultuur. Thuis worden deze jongens meestal keihard opgevoed door een autoritaire vader die hen alleen maar commandeert. Juist bij Marokkaanse jongens die wat minder sterk in de schoenen staan, over minder maatschappelijke bagage beschikken en een dik ego hebben, leidt dat tot conflicten, verzet en criminaliteit.' (ME, 16-9-2008: 2)

Slechts in sommige gevallen wordt dit toegelicht door te wijzen op vermeende culturele factoren als: 'wantrouwen', 'overlevingsmentaliteit' (VK, 16-9-2008: 12), 'slachtoffercultuur' (VK, 21-10-2008: 3), 'schaamte' (VK, 27-10-2007: 15), 'groepsgedrag' (vb. 1V, 19-9-2008) en 'verstikkende sociale controle' als het gaat om traditionele normen (VK, 16-9-2008: 12), maar 'gebrek aan sociale controle' als het gaat om overlast en criminaliteit (vb. PW, 3-10-2008). Daarnaast wordt gewezen op 'disfunctionele gezinnen' (TG, 23-10-2008: 8) binnen de Marokkaanse gemeenschap die zouden ontstaan door bijvoorbeeld: 'gedwongen huwelijken' (VK, 17-10-2007: 13), 'importhuwelijken' (ME, 29-1-2010: 6), 'echtscheidingen' (vb. VK, 24-10-2007: 11), 'slechte ouder-kindrelaties' (NO, 22-10-2008) en een 'slechte opvoeding' (vb. ME, 8-1-2010: 3). Een andere verklaring die de Marokkaanse cultuur aanwijst als een oorzaak is dat Marokkaans-Nederlandse jongeren tussen twee botsende culturen, de Nederlandse en Marokkaanse, zou- 
den leven, met een identiteitscrisis als gevolg, die het problematische gedrag zou veroorzaken (vb. ME, 16-9-2008: 2; VK, 26-10-2007: 11). De Marokkaanse cultuur wordt verder ook impliciet aangedragen als verklaring voor 'het Marokkanenprobleem' middels verwijzingen naar zogenaamde 'integratieproblemen' (vb. NO, 25-11-2008) en 'het immigratievraagstuk' (vb. PW, 1-12-2008) of door de minister van Integratie bij de gebeurtenissen aan te wijzen als de verantwoordelijke minister (vb. PW, 13-11-2007; VK, 31-10-2007: 18). Met deze 'gebrekkige integratie' wordt geïmpliceerd dat men de Nederlandse cultuur nog te weinig heeft overgenomen en/of te veel vasthoudt aan de uitheemse cultuur.

Naast de culturele verklaring worden ook verklaringen gegeven die zijn gebaseerd op sociaaleconomische factoren als laag opleidingsniveau (vb. 1V, 27-10-2007), schooluitval (vb. TG, 26-9-2008: 1), werkloosheid (vb. ME, 3-1-2008: 12), slechte huisvesting (vb. TG, 21-12-2007: 6) en armoede (vb. VK, 24-10-2007: 11), maar die vervolgens weer gekoppeld worden aan de Marokkaanse etniciteit:

'De problemen blijven niet beperkt tot de straat. Binnen de Marokkaanse bevolkingsgroep is er volgens Cohen [red. toenmalig burgemeester van Amsterdam] tevens sprake van veel probleemgezinnen en schooluitval; een derde van de kinderen doet niet mee aan de Citotoets.' (VK, 1-11-2007: 3)

'Verder staan zowel de Molukse als de Marokkaanse gemeenschap er slecht voor. Het gaat dan vooral om de jongens. Die scoren slecht op gebieden zoals onderwijs, arbeidsparticipatie en integratie. Daar moet wat aan gebeuren, zodat ze een diploma halen en aan het werk kunnen.' (toenmalig GroenLinksTweede Kamerlid, Naïma Azough: ME, 8-1-2010: 3)

\section{- De Marokkaan als folk saint}

De sociale constructie van 'de Marokkaan' in de media bestaat echter niet alleen uit negatieve beelden. In de maatschappelijke reactie zien we namelijk niet alleen een negatieve constructie als folk devil, maar ook een 'positieve' constructie als folk saint (Bouabid, 2010). Dit sociaal type is de eenduidige tegenhanger van de folk devil. Waar de folk devil de belichaming is van de negatieve 'ander' (Cohen, 2002: 2), is de folk saint juist de positieve 'ander', oftewel een door de dominante meerderheid aangewezen rolmodel voor de sociaal deviante minderheid (Bouabid, 2010). Deze constructie vindt plaats doordat bepaalde personen en hun gedragingen, bewust of onbewust, worden aangewezen als 'goede voorbeelden' en ze tegen de folk devils worden afgezet. In de reacties op de drie gebeurtenissen worden als folk saints enerzijds bekende personen aangewezen, zoals politici Ahmed Marcouch en Ahmed Aboutaleb (vb. VK, 3-11-2007: 2; TG, 1-11-2008: 5) en Oranjeinternational Ibrahim Afellay (PW, 17-10-2008) en anderzijds personen die in krantenartikelen of televisieprogramma's worden uitgelicht als dergelijke 'voorbeeld-Marokkanen', zoals jongerenwerkers (NO, 18-10-2007), buurtvaders (vb. VK, 17-10-2007: 1) en -moeders (vb. TG, 1-11-2007: 9) die zich actief bezighouden met het corrigeren van de folk devils en verder 'Marokkanen' die zich aan 'de regels' houden (1V, 19-9-2008), de Nederlandse taal beheersen (vb. PW, 17-12-2007), hoogopgeleid zijn (vb. VK, 14-10-2008: 12) of een bedrijfje runnen, 
zoals Ton Elias, toen nog aspirant-Tweede Kamerlid van de VVD, construeert (vb. PW, 17-9-2008):

'Kijk, wat ik er eng aan vind is dat, natuurlijk is dat wat er in Gouda is gebeurd, dat daar geen bus meer door een woonwijk kan rijden, dat is schande, daar moet glashard tegen worden opgetreden. Nou, zo kun je al die dingen die hij noemt, allemaal mee eens, maar maak er niet van dat alle Marokkanen in Nederland zo zijn. Als ik straks mijn winterbanden moet laten vervangen, dan ga ik naar een kleine garage toe, dat is twee jaar geleden overgenomen door een Marokkaanse jongen, die een boekhoudcursus heeft... en ik ben niet zo van de multiculti hoor, maar die heeft een boekhoudcursus gedaan, die heeft een Turk aangenomen en een Surinamer, en daar met zijn drieën zitten ze een bedrijfje te runnen. Dat zijn geen criminelen. Klaar. En Wilders doet alsof iedere Marokkaan een crimineel is. Daar heb ik grote bezwaren tegen.'

Daarnaast worden ook Nederlanders met een Turkse (vb. VK, 1-12-2007: 3), Surinaamse (PW, 25-9-2008) en Molukse achtergrond geconstrueerd als folk saints. Dit 'positieve' beeld ten aanzien van 'de Molukkers' wordt treffend samengevat door Volkskrant-columniste Nausicaa Marbe:

'Cru neergezet: De Marokkanen die zich misdragen en de Molukkers die keihard terugslaan, zijn niet enkel spelers in lokale, etnisch getinte schermutselingen. Ze lijken uitgegroeid tot symbolen voor een nationale plaag en haar verdelger: de intimidatie door Marokkaanse straatschuimers en de heroïek van andere allochtonen die, anders dan die slappe Nederlanders, van zich durven afbijten.' (VK, 8-1-2010: 11)

\section{De 'ware betekenis' van deze Marokkanenpaniek}

De maatschappelijke reacties op Marokkaans-Nederlandse jongeren in de media bevatten een aantal cruciale elementen van een morele paniek. Zo wordt de dreiging van de gebeurtenissen overdreven, doordat men feiten overdrijft, voorspellingen doet van dreigend gevaar en koppelingen zoekt met andere bestaande sociale bezorgdheden en angsten. Deze overdrijving gaat daarnaast gepaard met een symboliseringsproces waarin deze dreiging expliciet en impliciet wordt gekoppeld aan de Marokkaanse etniciteit en het reeds bestaande 'Marokkanenprobleem'. Hiermee wordt 'de Marokkaan' als folk devil aangewezen, waarbinnen hij met beelden en verklaringen wordt geconstrueerd als de morele en culturele 'ander' (othering). Deze maatschappelijke reacties zijn op basis van deze bevindingen te kenschetsen als een morele paniek over 'Marokkanen' in de media. Deze reacties lijken zich namelijk niet op criminaliteit en overlast in het algemeen te richten, maar specifiek op criminaliteit en overlast van 'de Marokkaan'. Het zijn deze koppelingen van enerzijds de Marokkaanse etniciteit en een deviante moraliteit en cultuur en anderzijds sociale problemen en angsten als overlast, criminaliteit, islamitisch 
radicalisme en immigratie binnen deze maatschappelijke reacties, die de misplaatsing van dezelfde maatschappelijke reacties blootleggen. De reacties lijken zich door dit steevast 'etniseren' en 'culturaliseren' (zie ook Schinkel, 2008) 'proportioneel' te richten op een gevoelde dreiging van aantasting van de heersende moraliteit van de dominante culturele meerderheid door deze etnische, culturele en religieuze 'ander'. Deze aantasting van de heersende moraal, die door de meerderheidscultuur als 'echt' wordt ervaren en ook zeer zeker serieus genomen moet worden (Scheffer, 2007), is dan ook het 'ware probleem' waar deze maatschappelijke reactie zich eigenlijk op richt. Dit autochtoon onbehagen (p. 37-47) uit zich dan echter 'disproportioneel' in misplaatste maatschappelijke reacties op criminaliteits- en overlastincidenten waarin Marokkaans-Nederlandse probleemjongeren een prominente rol spelen, zoals in Slotervaart en Culemborg, of zelfs helemaal geen rol spelen, zoals in Gouda.

Young (2007; 2009) geeft een verklaring voor dergelijke misplaatste maatschappelijke reacties. Volgens hem is een morele paniekreactie een 'natuurlijke' reactie van de meerderheidscultuur op morele en culturele veranderingen. Deze natuurlijke reactie, waarin een deviante moraliteit en cultuur worden bekritiseerd en afgewezen, behelst dan een indirecte bevestiging van de 'eigen' moraliteit en cultuur. De othering die deel uitmaakt van deze oplossing van de dominante meerderheid, zorgt bovendien voor een koppeling van sociale problemen aan 'de exogene ander', waarmee deze sociale problemen kunnen worden geconstrueerd als exogene en autonome problemen (de sociale problemen zijn een autonoom gevaar voor de maatschappij in plaats van dat ze voortkomen uit diezelfde maatschappij), waarmee ze buiten de 'normaal functionerende sociale orde' (Young, 2007: 142) of zoals Schinkel hetzelfde proces beschrijft, buiten het 'gezonde sociaal lichaam' worden geplaatst (2008).

Ten slotte impliceert de duiding van deze maatschappelijke reacties als morele paniek zeer zeker niet een bagatellisering of ontkenning van de oververtegenwoordiging van Marokkaans-Nederlandse jongeren in ernstige sociale problematiek. ${ }^{6}$ Integendeel. Deze duiding als morele paniek legt het 'ware probleem' bloot dat juist door deze misplaatste aandacht niet of nauwelijks geadresseerd, onderkend en/of opgelost wordt. Met deze benadering kan de focus weer van de actuele gebeurtenissen en sociale gedragingen worden verlegd naar dit onderliggende 'ware probleem'. Hierdoor kunnen vervolgens humanere reacties op, constructieve debatten over en effectiever beleid ten aanzien van dit 'ware probleem' ontstaan, namelijk de aantasting van de morele en culturele grenzen van de Nederlandse maatschappij, maar tegelijkertijd ook ten aanzien van de actuele gebeurtenissen en sociale gedragingen, in casu voornamelijk de overlastgevende en criminele gedragingen van een groep jongvolwassenen (Cohen, 2002: 172). Met de huidige morele paniekreactie op 'Marokkanen' in de media komen we helaas niet verder dan (een roep om) een harde(re) aanpak van deze jongvolwassenen zonder sociaal gezicht (zie bijvoorbeeld: NO, 19-10-2007; ME, 16-9-2008: 2; 1V,

6 De bagatellisering of ontkenning van problemen is een veelgehoorde, maar zeer onterechte kritiek op de morele paniektheorie, zie Cohen, 2002: viii. 
4-1-2010; zie ook Van Swaaningen, 2005) en een zorgwekkende stigmatisering van een hele bevolkingsgroep.

\section{Literatuur}

Adang, O., R. van der Wal \& H. Quint (2010), Zijn wij anders? Waarom Nederland geen grootschalige etnische rellen heeft. Apeldoorn: Politieacademie.

Altheide, D.L. \& C.J. Schneider (2013), Qualitative Media Analysis. Thousand Oaks: Sage.

Becker, H.S. (1963), Outsiders. Studies in the Sociology of Deviance. New York: Macmillan.

Blumer, H.G. (1954), What is wrong with social theory? American Sociological Review, 18, 3-10.

Bouabid, A. (2010), Moral panics \& folk devils in post-Van Gogh Nederland. Een studie naar de maatschappelijke reactie op de moord op Theo van Gogh. Rotterdam: ESL/Criminologie (master thesis).

Bouabid, A. (2016), Riots of the other: An analysis of the societal reactions to contemporary riots in disadvantaged neighbourhoods in the Netherlands. European Journal of Criminology, Special Issue on Riots (in press).

Bovenkerk, F. (2003a), Taboe in de criminologie. Proces. Tijdschrift voor berechting en reclassering, 5, 242-251.

Bovenkerk, F. (2003b), Paniekreacties op de criminaliteit van allochtone jongeren in Nederland en Australië. In: S. Harchioui \& C. Huinder (red.), Stigma: Marokkaan! Over afstoten en insluiten van een ingebeelde bevolkingsgroep. Utrecht: Forum, 39-62.

Bovenkerk, F. (2014), Marokkaan in Europa, crimineel in Nederland. Den Haag: Boom Lemma.

Buijs, F., F. Demant \& A. Hamdy (2006), Strijders van eigen bodem. Radicale en democratische moslims in Nederland. Amsterdam: Amsterdam University Press.

CBS StatLine (2013, 3 mei). Kerncijfers wijken en buurten 2004-2008. Geraadpleegd op 1 maart 2016 van: http://statline.cbs.nl/Statweb.

Cohen, S. (1972), Folk Devils and Moral Panics. The Creation of the Mods and Rockers. London: MacGibbon \& Kee.

Cohen, S. (2002), Folk Devils and Moral Panics. The Creation of the Mods and Rockers (3e editie). London: Routledge.

Critcher, C. (2003), Moral Panics and the Media. Buckingham: Open University Press.

Ferrell, J., K. Hayward \& J. Young (2008), Cultural Criminology. An Invitation. London: Sage Publications.

Ferrell, J., K. Hayward \& J. Young (2015), Cultural Criminology. An Invitation (2e editie). London: Sage Publications.

Garland, D. (2008), On the concept of moral panic. Crime, Media \& Culture, 4(1), 9-30.

Hall, S., C. Critcher, T. Jefferson, J. Clarke \& B. Roberts (1978), Policing the Crisis. Mugging, the State, and Law and Order. London: Macmillan.

Hennink, M., I. Hutter \& A. Bailey (2011), Qualitative Research Methods. London: Sage.

Jong, D. de (2007), Kapot moeilijk. Amsterdam: Aksant.

Krinsky, C. (2013), Introduction. The moral panic concept. In: C. Krinsky, The Ashgate Research Companion to Moral Panics. Farnham: Ashgate Publishing Limited, 1-14.

Loef, K. (1988), Marokkaanse daders in de Amsterdamse binnenstad. Amsterdam: Gemeente Amsterdam.

Maas-de Waal, C.J. (1991), Wetenschappelijk onderzoek naar criminaliteit van allochtonen; een taboe doorbroken? Tijdschrift voor Criminologie, 3, 277-300. 
Nijpels B. \& H. van de Beek (verslaggevers) (2012, 19 september). Gouda: Een probleem van tien miljoen [videobestand]. In: Argos TV - Medialogica. Hilversum: HUMAN/ VPRO. Geraadpleegd op 24 februari 2016, van: www.npo.nl/argos-tv-medialogica/19 -09-2012/VPWON_1177985.

Scheffer, P. (2007), Het land van aankomst. Amsterdam: Bezige Bij.

Schinkel, W. (2008), De gedroomde samenleving. Kampen: Klement.

Swaaningen, R. van (2005), Public safety and the management of fear. Theoretical Criminology, 9, 289-305.

Swaaningen, R. van (2006), Criminology in the Netherlands. European Journal of Criminology, 3 (4), 463-501.

Vasterman, P. (2004), Mediahype. Amsterdam: Aksant.

Werdmölder, H. (1989), Een taboe doorbroken. Marokkaanse jongeren en criminaliteit. Intermediair, 25(12), 17-23.

Young, J. (1971a), The Drugtakers: The Social Meaning of Drug Use. London: McGibbon and Kee.

Young, J. (1971b), The role of the police as amplifiers of deviancy, negotiators of reality and translators of fantasy. In: S. Cohen (1971), Images of Deviance. Harmondsworth: Penguin Books.

Young, J. (1997), Breaking windows. Situating the new criminology. In: P. Walton \& J. Young (ed.), The New Criminology Revisited. Basingstoke: Macmillan.

Young, J. (2005), Book Review: Moral panics, Margate and Mary Poppins: Mysterious happenings in south coast seaside towns. Crime, Media, Culture, 1(1), 100-105.

Young, J. (2007), The Vertigo of Late Modernity. London: Sage.

Young, J. (2009), Moral panic: Its origins in resistance, ressentiment and the translation of fantasy into reality. The British Journal of Criminology, 49(1), 1-3.

Young, J. (2011), Moral panics and the transgressive other. Crime, Media, Culture, 7(3), 245-258. 